\title{
ERRATUM - Male circumcision and prostate cancer (Table 3)
}

Cite as: Can Urol Assoc J 2021;15(3):E196. http://dx.doi.org/10.5489/cuaj.7192

$\mathrm{n}$ response to a reader query regarding a recently published paper entitled, "Male circumcision and prostate cancer: A geographical analysis, meta-analysis, and cost analysis," (Citation: Van Howe RS. Can Urol Assoc J 2020;14(7):E334-40. http://dx.doi.org/10.5489/cuaj.6126), a statistical re-review was conducted and an apparent mislabeling of the column headings in Table 3 was identified. The author revised the table with the correct column headings (below).

Please visit https://cuaj.ca/index.php/journal/article/view/6126/4513 for a corrected version of the full manuscript. CUAJ regrets the oversight and apologizes for any inconvenience.

\begin{tabular}{|c|c|c|c|c|c|c|}
\hline Study & Intact case & $\begin{array}{l}\text { Circumcised } \\
\text { case }\end{array}$ & Intact control & $\begin{array}{l}\text { Circumcised } \\
\text { control }\end{array}$ & $\begin{array}{l}\text { Odds } \\
\text { ratio }\end{array}$ & $\begin{array}{c}95 \% \text { confidence } \\
\text { interval }\end{array}$ \\
\hline Kaplan & 34 & 19 & 90 & 61 & 1.21 & $0.63,2.32$ \\
\hline Wynder & 143 & 29 & 121 & 21 & 0.86 & $0.46,1.58$ \\
\hline Rotkin & 52 & 59 & 54 & 57 & 0.93 & $0.55,1.58$ \\
\hline Ross - White & 81 & 61 & 57 & 85 & 1.98 & $1.23,3.18$ \\
\hline Ross - Black & 99 & 43 & 84 & 58 & 1.59 & $0.97,2.59$ \\
\hline Mandel & 124 & 102 & 137 & 103 & 0.91 & $0.63,1.32$ \\
\hline Newell & 50 & 44 & 114 & 53 & 0.53 & $0.31,0.89$ \\
\hline Ewings & 123 & 36 & 221 & 104 & 1.61 & $1.04,2.49$ \\
\hline Rosenblatt & 253 & 500 & 215 & 488 & 1.15 & $0.92,1.43$ \\
\hline Madsen & 85 & 1 & 99 & 4 & 3.43 & $0.38,31.32$ \\
\hline Wright & 294 & 707 & 254 & 688 & 1.03 & $0.92,1.37$ \\
\hline Spence - White & 814 & 526 & 790 & 525 & 1.03 & $0.88,1.20$ \\
\hline Spence - Black & 81 & 22 & 44 & 31 & 2.59 & $1.34,3.63$ \\
\hline Spence-Asian & 19 & 6 & 50 & 20 & 1.05 & $0.44,5.01$ \\
\hline Spence - other & 42 & 33 & 59 & 53 & 1.14 & $0.64,2.06$ \\
\hline Nair-Shalliker & 389 & 931 & 296 & 712 & 1.01 & $0.84,1.20$ \\
\hline Random-effects summary effects OR & & & & & 1.10 & $0.96,1.26$ \\
\hline
\end{tabular}

